INFORMACIÓN AL PACIENTE

\author{
Sección coordinada por: \\ V. F. Moreira y E. Garrido \\ Servicio de Gastroenterología. Hospital Universitario Ramón y Cajal. Madrid
}

\title{
Dolor abdominal funcional
}

\section{QUÉ ES}

Se entiende por dolor abdominal funcional un dolor continuo o casi continuo localizado en el abdomen y que no suele tener relación con la función del intestino, es decir, que no se modifica con la comida o la defecación. Este dolor no está causado por ninguna patología o enfermedad de ningún órgano abdominal. Como para el resto de patología funcional existen unos criterios clínicos (denominados de Roma III) para su diagnóstico.

Criterios de Roma III para el diagnóstico del dolor abdominal funcional:

1. Dolor abdominal continuo o casi continuo.

2. Ninguna o solo una relación ocasional del dolor con eventos fisiológicos (comer, defecar o menstruación).

3. Alguna repercusión en la vida diaria del paciente.

4. El dolor no es fingido.

5. Síntomas insuficientes para cumplir criterios de otro trastorno gastrointestinal funcional.

Los criterios deben cumplirse en los últimos tres meses con síntomas presentes al menos 6 meses antes del diagnóstico.

Es relativamente poco frecuente, predomina en mujeres y suele aparecer hacia los 40 años.

\section{MOLESTIAS QUE OCASIONA}

El dolor abdominal no tiene características ni localización especial. Suele ser difuso y puede tener características variables: opresión, "como una puñalada" o más vago. Es una característica fundamental que no se modifica con las comidas, ni con el ir de vientre o la menstruación. Permite el sueño y no suele acompañarse de una pérdida de peso importante ni de otros síntomas abdominales (náuseas, vómitos, cambio en el hábito deposicional). Es bastante característico que estos pacientes tengan otros cuadros dolorosos inespecíficos a lo largo de su vida (fibromialgia, dolores de cabeza, etc.).

\section{POR QUÉ SE PRODUCE}

No se conoce la causa de este trastorno, sin embargo la asociación frecuente del dolor abdominal funcional con otro tipo de enfermedades dolorosas como la fibromialgia, dolores de espalda y de cabeza entre otros y la asociación con enfermedades psicológicas o psiquiátricas como la ansiedad, depresión o somatización orientan hacia una alteración del sistema nervioso como una mala regulación y control del dolor.

\section{CÓMO SE DIAGNOSTICA}

El diagnóstico del dolor abdominal funcional se basa en las características del dolor y, en algunas ocasiones, excluir otras enfermedades que pueden producir molestias similares. Las exploraciones necesarias para llegar al diagnóstico de dolor abdominal funcional son muy variables y dependen fundamentalmente de la intensidad del dolor, su duración y síntomas acompañantes. Si el dolor es de larga evolución, sin repercusión en la vida normal del individuo (sin pérdida de peso y con poca repercusión en su calidad de vida, como por ejemplo no perder días de trabajo o actividades cotidianas) la historia clínica y la exploración física normal serían suficientes para establecer el diagnóstico. Por el contrario, si el dolor es muy intenso acompañado de absentismo laboral, o bien se acompaña de otros síntomas que hagan sospechar alguna enfermedad concreta se tendrán que excluir enfermedades abdominales que incluyen fundamentalmente enfermedades digestivas, ginecológicas y urinarias. Las pruebas que se realizarán son muy variadas y se decidirán a criterio del médico y basándose en las características de cada paciente; pueden incluir: fibrogastroscopia, colonoscopia, ecografía y/o TAC abdominal, exploración ginecológica y urológica.

\section{CÓMO SE TRATA}

Lamentablemente no hay tratamiento definitivo o curativo para el dolor abdominal funcional. Un factor importante para el paciente es saber de la naturaleza benigna de su enfermedad, es decir, que aunque sea un proceso crónico no implica riesgo para la vida del paciente ni riesgo de intervenciones quirúrgicas por este motivo. Los medicamentos que habitualmente se utilizan en el tratamiento del dolor (analgésicos) como Aspirina o antiinflamatorios, no son de utilidad y por lo tanto no deben utilizarse por sus posibles efectos secundarios. El tratamiento más utilizado es mediante fármacos que actúen a nivel del sistema nervioso central y abdominal; los más utilizados son los antidepresivos que tienen una acción doble: tratar el dolor que posiblemente se origine del sistema nervioso abdominal y mejorar el posible componente psicológico del paciente. Hay varias familias de antidepresivos que pueden utilizarse, algunos de ellos a dosis inferiores a las habitualmente utilizadas para la depresión. Si el paciente tiene una alteración psicológica asociada cono cuadro de ansiedad, depresión entre otros, tendrá que añadirse un tratamiento adecuado. Hay que evitar en lo posible el utilizar tratamiento con morfina o sus derivados ya que crean dependencia importante.

\section{PRONÓSTICO}

El pronóstico no es malo en cuanto el dolor abdominal funcional no pone en peligro la vida del enfermo. El paciente tiene que ver esta dolencia como cualquier proceso doloroso crónico y benigno: cefalea tensional, dolores óseos, etc. Con la evolución suele disminuir la intensidad y la frecuencia del dolor.

Anna Accarino

Servicio de Aparato Digestivo. Hospital Universitario Valle Hebrón. Barcelona 